\title{
Stage IVB Bone Cancer AJCC v8
}

National Cancer Institute

\section{Source}

National Cancer Institute. Stage IVB Bone Cancer A/CC v8. NCI Thesaurus. Code

C136622.

Stage IVB includes: (Any T, N1, Any M, Any G); (Any T, Any N, M1 b, Any G). N1: Regional

lymph node metastasis. M1b: Metastasis in the bone or other distant sites. (AJCC 8th ed.) 